\title{
Postharvest Water Loss and Storage Quality of Nine Pepper (Capsicum) Cultivars
}

\author{
N.K. Lownds, M. Banaras, and P.W. Bosland \\ Department of Agronomy and Horticulture, New Mexico State University, Las \\ Cruces; NM 88003
}

Additional index words. chile peppers, modified-humidity packaging, shipping

\begin{abstract}
Nine pepper cultivars (Capsicum annuum L.) representing five pepper types were studied to determine water-loss rates, flaccidity, color, and disease development when stored at 8,14 , or $20 \mathrm{C}$ for 14 days. Water-loss rate was markedly higher at $14 \mathrm{C}$ than at $8 \mathrm{C}$, and was somewhat lower at $20 \mathrm{C}$ than at $14 \mathrm{C}$. There were significant differences in waterloss rates between pepper cultivar with 'NuMex R Naky', 'NuMex Conquistador', and 'New Mexico 6-4' (New Mexican-type peppers) having the highest water-loss rates. Flaccidity followed a pattern similar to water loss at each storage temperature, suggesting a direct relationship. Color development was cultivar- and package-dependent, and ratings increased with temperature. Placing pepper fruit in perforated polyethylene packages reduced water-loss rates 20 times or more, so that water loss no longer limited postharvest storage. Packaging also eliminated flaccidity and reduced color development across cultivars at 14 and 20C. Packaged fruit, however, developed diseases that limited postharvest longevity.
\end{abstract}

Demand for fresh pungent peppers has greatly increased as southwestern foods have become the most popular ethnic food in the United States (DeWitt, personal communication). However, fresh New Mexican-type peppers, a major ingredient in southwestern foods, have a shelf-life of only a few days. Extending postharvest longevity to meet the demand for fresh peppers requires an understanding of storage characteristics and factors affecting storage.

Peppers rapidly lose water after harvest, limiting longevity (Anandaswamy et al., 1959; Ryan and Lipton, 1972; Showalter, 1973; Watada et al., 1987). New Mexican-type peppers become flaccid in 3 to 5 days at $20 \mathrm{C}$ ( $7 \%$ to $10 \%$ weight loss) and lose water twice as fast as bell or jalapeño types (Lownds and Bosland, 1988)

To our knowledge, no work examines the effects of postharvest storage temperature and packaging on New Mexican-type peppers. Using a polyethylene shrink wrap to produce a water-saturated atmosphere and decrease transpirational water loss has been an effective method of increasing postharvest life of some tree fruit (Ben-Yehoshua, 1985). Polyethylene packages also produce a modified gaseous atmosphere around the fruit, which can further increase storage longevity (Cameron et al., 1989; Forney et al., 1989). Seal-packaged fruit stored at 20C lost less weight and were more turgid than nonsealed fruit at the optimal stor-

Received for publication 10 Apr. 1993. Accepted for publication 6 Aug. 1993. This research was supported by the New Mexico Agricultural Experiment Station. The cost of publishing this paper was defrayed in part by the payment of page charges. Under postal regulations, this paper therefore must be hereby marked advertisement solely to indicate this fact. age temperature and $85 \%$ relative humidity (RH) (Ben-Yehoshua et al., 1982). Several postharvest storage techniques should be applicable to New Mexican-type peppers, but their use and optimization requires an understanding of postharvest changes influencing longevity of these peppers. Therefore, studies were initiated to characterize postharvest water loss and storage quality of pungent pepper types, as well as bell peppers, in relation to storage temperature and packaging.

\section{Materials and Methods}

Fresh, green, mature bell ('Keystone' and 'Mexibell'); New Mexican ('NuMexRNaky', 'NuMex Conquistador', and 'New Mexico 64'); yellow wax ('Santa Fe Grande' and 'Cascabella'); jalapeño('TAM Jalapeño'); and serrano ('TAM Hidalgo' ) peppers were harvested from plants grown under standard cultural practices (Bosland et al., 1991) at the Leyendecker Plant Science Research Center (Las Cruces, N.M.). Fresh, mature fruit without visible defects were hand-picked, placed in plastic bags, and taken to the laboratory. for nine pepper cultivars stored for 14 days at 8,14 , or $20 \mathrm{C}$.

${ }^{2}$ Different values within columns differ significantly at $P \leq 0.01$.
Fruit were washed with distilled water, airdried, and randomized for each treatment. Each replication consisted of two bell-type and New Mexican-type fruit, five yellow waxtype fruit, and seven jalapeño- and serranotype fruit (similar total fruit weight). The fruit were stored either nonpackaged or packaged (low-density polyethylene, $17.5 \times 20 \times 0.0044$ $\mathrm{cm})$ at 8,14 , or $20 \mathrm{C}$ for 14 days. Each package contained eight 26 -gauge needle holes $\approx 1 \mathrm{~mm}$ in diameter), adequate to maintain a $20 \% \mathrm{O}_{2}$ atmosphere (A. Cameron, Michigan State Univ., personal communication). Ambient RH was $75 \%$ at each temperature, resulting in vapor pressure deficits of $0.21,0.32$, and 0.47 $\mathrm{kPa}$ at 8,14 , and $20 \mathrm{C}$, respectively. Each treatment was replicated three times.

Fruit were weighed before storage and again every $24 \mathrm{~h}$ for 14 days. Percent weight loss and rate of weight loss were calculated. Flaccidity (firmness decrease), color development, and disease were rated daily. Flaccidity was determined by subjectively measuring surface depression to applied finger pressure and assigning this a quantitative score, ranging from 0 to $9: 0=$ hard, $1=$ isolated softness, $<10 \%$ of fruit; $3=$ isolated soft areas, $<25 \%$ of fruit $5=50 \%$ of fruit soft $7=75 \%$ of fruit soft; and $9=$ completely soft (Risse and Miller, 1986). Packaged fruit were not removed from the package, and care was taken to avoid damaging the fruit. Color development was subjectively scored on a scale of $\mathrm{O}$ to $9: 0=$ $100 \%$ green; $1=$ slight coloration; $3=25 \%$ red; $5=50 \%$ red; $7=7570$ red; and $9=100 \%$ red. Disease rating was scored on a scale of 0 to $9: 0=$ none; $1=$ slight on stern, $3=$ moderate on stem; $5=$ severe on stem plus calyx; $7=$ slight on fruit; and 9 = severe on fruit. Even numbers represented intermediate responses.

Water-loss data were subjected to stepwise linear regression analysis using Statistical Analysis System (SAS Institute, 1982). Flaccidity, color, and disease ratings were analyzed as a split plot, assigning cultivars to main plots and packaging to subplots for each temperature. Treatments were compared using Fisher's LSD test.

\section{Results and Discussion}

Water-loss rates of nonpackaged fruit varied from $1.4 \%$ to $13.9 \%$ per day per kpa depending on storage temperature and cultivar (Table 1). Cultivar differences were apparent

Table 1. Effect of storage temperature and packaging on weight loss (percent weight loss/day per kiloPascal)

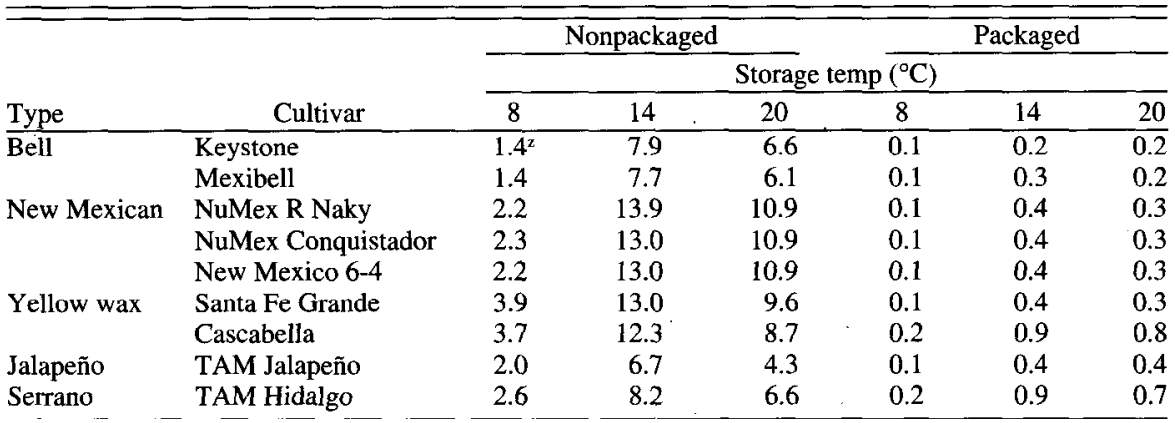


Table 4. Effect of storage temperature on disease rating for packaged fruit of nine pepper cultivars following 14 days of storage at 8,14 , or $20 \mathrm{C}$.

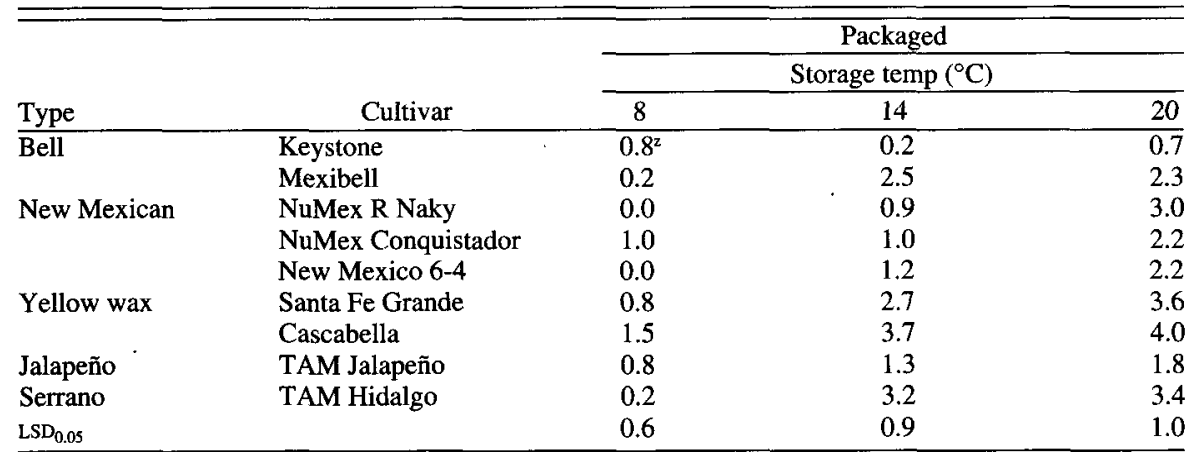

Disease rating: $0=$ none; $1=$ slight on stem; $3=$ moderate on stem; $5=$ severe on stem plus calyx; $7=$ slight on fruit $9=$ severe on fruit.

Understanding the effects of storage temperature and packaging on postharvest water loss and storage quality of pungent pepper cultivars should provide a basis for optimizing postharvest storage techniques. Water loss is the overriding factor influencing postharvest longevity, and it can directly affect several other factors. Special consideration should be given to the marked changes that occur when nonpackaged peppers are stored at $>8 \mathrm{C}$. Eliminating water loss through packaging holds great potential for pungent pepper storage even at temperatures $>8 \mathrm{C}$. Further study will be required to optimize packaging conditions, especially relative to disease control.

\section{Literature Cited}

Anandaswamy, B., H.B.N. Murphy, and N.V.R Iyengar. 1959. Prepackaging studies on fresh produce: Capsicum annuum var. grossum (Sendt.) and Capsicum annuum var. acuminatum (Fingh.). J. Sci. Ind. Res. 18:274-278.

Ben-Yehoshua, S. 1985. Individual seal-packaging of fruit and vegetables in plastic film-A new postharvest technique. HortScience 2032-37.

Ben-Yehoshua, S. 1987. Transpiration, water stress, and gas exchange, p. 11 3-170. In: J. Weichmau (ed.). Postharvest physiology of vegetables. Marcel Dekker, New York.

Ben-Yehoshua, S., B. Shapiro, J.E. Chen, and S. Lurie. 1983. Mode of action of plastic film in extending life of lemon and bell pepper fruits by alleviation of water stress. Plant Physiol. 73:8793.
Ben-Yehoshua, S., B. Shapiro, and I. Kobiler. 1982. New method of degreening lemons by a combined treatment of ethylene-releasing agents and seal-packaging in high density polyethylene film. J. Amer. Soc. Hort. Sci. 107:365-369.

Bosland, P.W., A.L. Bailey, and D.J. Cotter. 1991. Growing chiles in New Mexico. New Mexico State Univ. Coop. Ext. Guide H-230.

Cameron, A. C., W. Boylan-Pett, and J. Lee. 1989. Design of modified atmosphere packaging systems: Modeling oxygen concentrations within sealed packages of tomato fruits. J. Food Sci. 54:1413-1416.

Cameron, A.C. and S.F. Yang. 1982. A simple method for determination of resistance to gas diffusion in plant organs. Plant Physiol. 70:2123.

Forney, C.F., R.E. Rij, and S.R. Ross. 1989. Measurement of broccoli respiration rate in filmwrapped packages. HortScience 24:111-113.

Gross, K. C., A.E. Watada, M.S. Kang, S.D. Kim, K.S. Kim, and S.W. Lee. 1986. Biochemical changes associated with the ripening of hot pepper fruit. Physiol. Plant. 66:31-36.

Lester, G.E. and B.G. Bruton. 1986. Relationship of netted muskmelon fruit water loss to postharvest storage life. J. Amer. Soc. Hort. Sci. 111:727-731.

Lownds, N.K. and P.W. Bosland. 1988. Studies on postharvest storage of pepper fruits. HortScience 23:71. (Abstr.)

Lu, G., C. Yang, H. Liang, and Z. Lu. 1990. 'Changiiao' hot peppers are nonclimacteric. HostScience 25:807.

Maiero, M. and C. Waddell. 1991. Postharvest diseases of packaged green chile peppers. HostScience 26:694. (Abstr.)
Miller, W.R., L.A. Risse, and R.E. McDonald. 1986. Deterioration of individually wrapped and nonwrapped bell peppers during long-term storage. Trop. Sci. 26:1-8.

Miller, W. R., D.H. Spalding, L.A. Risse, and C. Chew. 1984. The effect of an imazalil to control decay of bell peppers. Proc. Fla. State Hort. Soc. 97:108-110

Monselise, S.P. 1981. Effects of climatic district, orchard treatment and seal-packaging on citrus fruit quality and storage ability. Proc. Intl. Citrus Congr., Tokyo. vol. 2.

Paull, R.E. and N.J. Chen. 1989. Waxing and plastic wraps influence water loss from papaya fruit during storage and ripening. J. Amer. Soc. Hort. Sci. 114:937-942.

Risse, R.A. and W.R. Miller. 1986. Individual film wrapping of fresh Florida cucumbers, eggplant, peppers and tomatoes for extending shelf life. J. Plastic Film \& Sheeting 2:164171.

Ryan, A.L. and W.J. Lipton. 1972. Handling, transportation and storage of fruits and vegetables. vol. 1. AVI, Westport, Corm. p. 11-14.

Saltveit, M. E., Jr. 1977. Carbon dioxide, ethylene, and color development in ripening mature green bell peppers. J. Amer. Soc. Hort. Sci. 102:523525.

Sanford, K.A., P.D. Lister, K.B. MeRae, E.D. Jackson, R.A. Lawrence, R. Stark, and P.K. Prange. 1991. Lowbush blueberry quality changes in response to mechanical damage and storage temperature. J. Amer. Soc. Hort. Sci. 116:4751.

SAS Institute. 1982. SAS user's guide: Statistics. SAS Inst., Cary, N.C.

Sastry, S. K., C.D. Baird, and D.E. Buffington. 1978. Transpiration rates of certain fruits and vegetables. Amer. Soc. Heating, Refrigerating and Eng. Trans. 84:237-255.

Shirazi, A. and A.C. Cameron. 1992. Controlling relative humidity in modified atmosphere packages of tomato fruit. HortScience 27:336-339.

Showalter, R.K. 1973. Factors affecting pepper firmness. Proc. Fla. State Hort. Soc. 86:230-232.

Watada, A.E., S.D. Kim, K.S. Kim, and T.C. Harris. 1987. Quality of green berms, bell peppers, and spinach stored in polyethylene bags. J. Food Sci. 52:1637-1641.

Wills, R. B. H., T.H. Lee, D. Graham, W.B. McGlasson, and E.G. Hall. 1981a. Physiology and biochemistry, p. 17-18. In: Postharvest: An introduction to the physiology and handling of fruits and vegetables. AVI, Westport, Conn.

Wills, R. B. H., T.H. Lee, D. Graham, W.B. McGlasson, and E.G. Hall. 1981b. Water loss and humidity, p. 52-59. In: Postharvest: An introduction to the physiology and handling of fruits and vegetables. AVI, Westport, Conn. 
at each storage temperature. The highest water-loss rates were 2- to 2.5-fold greater than the lowest rates for each storage temperature, with bell types having the lowest water-loss rates (Table 1). Packaging fruit reduced the water-loss rate 20 times or more at each storage temperature. For packaged fruit there were significant differences in water-loss rates among cultivars within a storage temperature, but water-loss rates were so low that they would be minimally important in practical applications. Water-loss rates were markedly higher at $14 \mathrm{C}$ than at $8 \mathrm{C}$ for all cultivars, nonpackaged or packaged, while water-loss rates were the same or somewhat lower at $20 \mathrm{C}$ than at $14 \mathrm{C}$ (Table 1).

Postharvest water loss was the primary factor limiting postharvest longevity for all pepper cultivars. Other factors became limiting only under conditions of low water-loss rates (storage at $8 \mathrm{C}$ or packaged). Therefore, efforts to increase postharvest longevity must begin with limiting water loss.

Fruit water loss is the result of fruit respiration and diffusion through the fruit cuticle. While not measured directly, fruit respiration probably played a minor role in water loss because peppers are nonclimacteric (Lu et al., 1990; Saltveit, 1977).

Water loss by diffusion is controlled by the water potential gradient from inside to outside the fruit and by the resistances to diffusion. The water potential gradient would be a function of storage temperature and RI-I, while diffusional resistances would be associated with the fruit cuticle. Differences in water loss among cultivars at each storage temperature or when packaged (Table 1) would suggest differences in cuticular permeability. These differences were primarily between pepper types (Table 1) and may have been related to fruit maturity or genetic differences such as cuticle thickness; presence of pores and/or cracks; and epicuticular wax quantity, distribution, or chemistry. Alternatively, the differences may be due to differences in fruit surface area : volume ratios (Ben-Yehoshua, 1987; Sastry et al., 1978; Wills et al., 1981a, 1981 b). Separating these possibilities and determining specific differences and their role in water loss will require further detailed study.

Flaccidity ratings, following 14 days of nonpackaged storage, ranged from 1.0 to 2.0 at $8 \mathrm{C}$, from 6.7 to 9.0 at $14 \mathrm{C}$, and from 6.5 to 9.0 at 20C (Table 2). Significant differences in flaccidity among cultivars were noted at each storage temperature. Flaccidity ratings increased 4.5- to 9-fold for fruit stored at $14 \mathrm{C}$ relative to those at $8 \mathrm{C}$, while the rating was similar for fruit at 14 and 20C (Table 2). Fruit stored in packages did not become flaccid at any temperature, even following 25 days of storage (data not presented). Flaccidity development appears to be directly associated with water loss.

Fruit color development following 14 days of storage depended on cultivar, storage temperature, and packaging. A significant cultivar $x$ package interaction occurred at 8 and 20C (Table 3). Differences were significant among nonpackaged cultivars at each storage tem-

Table 2. Effect of storage temperature on flaccidity rating for nonpackaged fruit of nine pepper cultivars following storage for 14 days at 8,14 , or $20 \mathrm{C}$.

\begin{tabular}{llccr}
\hline & & \multicolumn{2}{c}{ Storage temp $\left({ }^{\circ} \mathrm{C}\right)$} \\
\cline { 3 - 5 } Type & \multicolumn{1}{c}{ Cultivar } & 8 & 14 & 20 \\
\hline Bell & Keystone & $1.1^{2}$ & 7.3 & 7.7 \\
New Mexican & Mexibell & 1.0 & 7.5 & 8.2 \\
& NuMex R Naky & 1.0 & 9.0 & 9.0 \\
& NuMex Conquistador & 1.3 & 8.7 & 9.0 \\
Yellow wax & New Mexico 6-4 & 1.0 & 9.0 & 9.0 \\
& Santa Fe Grande & 2.0 & 8.8 & 9.0 \\
Jalapeño & Cascabella & 1.8 & 8.5 & 9.0 \\
Serrano & TAM Jalapeño & 1.4 & 6.7 & 6.5 \\
LSD & TAM Hidalgo & 1.7 & 9.0 & 8.7 \\
\hline
\end{tabular}

${ }^{2}$ Firmness rating based on a 0 to 9 scale where $0=$ firm and $9=$ soft.

Table 3. Effect of storage temperature and packaging on color rating for nine pepper cultivars following 14 days of storage at 8,14 , or $20 \mathrm{C}$.

\begin{tabular}{|c|c|c|c|c|c|c|c|}
\hline \multirow[b]{3}{*}{ Type } & \multirow[b]{3}{*}{ Cultivar } & \multicolumn{4}{|c|}{ Storage temp $\left({ }^{\circ} \mathrm{C}\right)$} & \multicolumn{2}{|c|}{-} \\
\hline & & \multicolumn{2}{|c|}{8} & \multicolumn{2}{|c|}{14} & \multicolumn{2}{|c|}{20} \\
\hline & & $\mathrm{NP}^{z}$ & $\mathrm{P}^{\mathbf{z}}$ & NP & $\mathbf{P}$ & NP & $\mathbf{P}$ \\
\hline \multirow[t]{2}{*}{ Bell } & Keystone & $1.3^{y}$ & 1.6 & 6.3 & 2.3 & 7.7 & 3.9 \\
\hline & Mexibell & 3.0 & 2.0 & 7.8 & 5.2 & 8.3 & 9.0 \\
\hline \multirow[t]{3}{*}{ New Mexican } & NuMex R Naky & 3.7 & 2.0 & 9.0 & 7.7 & 9.0 & 6.5 \\
\hline & NuMex Conquistador & 2.2 & 2.0 & 6.8 & 2.3 & 9.0 & 2.7 \\
\hline & New Mexico 6-4 & 2.5 & 2.2 & 9.0 & 5.8 & 9.0 & 4.5 \\
\hline \multirow[t]{2}{*}{ Yellow wax } & Santa Fe Grande & 2.8 & 1.8 & 8.8 & 3.0 & 9.0 & 4.2 \\
\hline & Cascabella & 2.3 & 2.1 & 8.5 & 3.2 & 9.0 & 5.2 \\
\hline Jalapeño & TAM Jalapeño & 2.0 & 1.7 & 4.7 & 1.8 & 5.3 & 2.1 \\
\hline Serrano & TAM Hidalgo & 2.7 & 2.3 & 6.0 & 2.2 & 9.0 & 4.2 \\
\hline \multicolumn{2}{|l|}{$\begin{array}{l}\mathrm{LSD}_{0.0 S} \\
\text { Significance }\end{array}$} & \multicolumn{2}{|c|}{0.7} & \multicolumn{2}{|c|}{2.4} & \multicolumn{2}{|c|}{1.4} \\
\hline \multicolumn{2}{|l|}{ Cultivar } & \multicolumn{2}{|c|}{0.058} & \multicolumn{2}{|c|}{0.001} & \multicolumn{2}{|c|}{0.001} \\
\hline \multicolumn{2}{|c|}{ Package } & \multicolumn{2}{|c|}{0.001} & \multicolumn{2}{|c|}{0.001} & \multicolumn{2}{|c|}{0.001} \\
\hline \multicolumn{2}{|c|}{ Cultivar $\times$ package } & \multicolumn{2}{|c|}{0.015} & \multicolumn{2}{|c|}{0.239} & \multicolumn{2}{|c|}{0.001} \\
\hline
\end{tabular}

${ }^{2}$ Nonpackaged (NP) or packaged (P).

Color rating based on $0=100 \%$ green and $9=100 \%$ red.

perature. For packaged fruit, cultivar differences were apparent only at 14 and 20C (Table 3 ). The fruit color rating for nonpackaged fruit increased 2.4- to 3.7-fold for fruit stored at $14 \mathrm{C}$ rather than at $8 \mathrm{C}$ and was almost the same at 14 and $20 \mathrm{C}$. For packaged fruit, the rating at $14 \mathrm{C}$ was about twice that at $8 \mathrm{C}$, and it was 1.4 times as high at $20 \mathrm{C}$ as at $14 \mathrm{C}$ (Table 3). Packaging fruit decreased color development for all cultivars at 14 or $20 \mathrm{C}$. At $8 \mathrm{C}$, however, packaging generally decreased color only slightly and increased fruit color relative to nonpackaged fruit for several cultivars.

The higher color rating at 14 or $20 \mathrm{C}$ relative to $8 \mathrm{C}$ (Table 3 ) paralleled differences in water-loss rates (Table 1) and suggests a direct relationship between these variables, as proposed by Ben-Yehoshua et al. (1983). Packaging fruit slowed color development (Table 3) for most cultivars, as in other studies (BenYehoshua et al., 1983). Since our packages contained eight 1-mm needle holes, presumably adequate to maintain internal package atmosphere equal to ambient gas concentrations (A. Cameron, Michigan State Univ., personal communication), the packaging effect on color development was probably not related to changes in the $\mathrm{CO}_{2}, \mathrm{O}_{2}$, and ethylene atmospheres around the fruit. In addition, although some hot peppers exhibit a climacteric-type pattern of ethylene production (Gross et al., 1986) and respond to exogenous ethylene with a climacteric-like rise in respiration (Lu et al., 1990), the amount of ethylene pro- duction is low and under our conditions would not be expected to accumulate or to induce changes in fruit respiration. The slow color development may instead be related to decreased water stress. At $8 \mathrm{C}$, where water stress was lowest, packaging had the smallest effect on color development. The significant cultivar differences suggest differential cultivar sensitivity to water stress, stress-induced responses, or both. Separation of these differences will require further study and should be considered in selecting peppers for their storage potential.

Postharvest diseases developed on packaged fruit at all storage temperatures (Table 4), while disease development on nonpackaged fruit was minimal (data not presented). There were cultivar differences in disease rating at each storage temperature. Fruit stored at $14 \mathrm{C}$ relative to $8 \mathrm{C}$ and at $20 \mathrm{C}$ relative to $14 \mathrm{C}$ showed approximately equal differences in disease rating, 1.5-fold.

Disease became the primary factor limiting postharvest longevity for packaged fruit. This has been observed for bell pepper (Miller et al., 1984), New Mexican-type peppers (Maiero and Waddell, 1991), and other commodities (Monselise, 1981; Risse and Miller, 1986), and may result from the water-saturated atmosphere inside the package. Methods to regulate RI-J within packages are being investigated currently (Shirazi and Cameron, 1992). Again, cultivar differences maybe important to consider in selecting peppers for postharvest storage. 